\title{
Advanced Manufacturing Technology Adoption in SMEs: an Integrative Model
}

\author{
Mirmahdi Darbanhosseiniamirkhiz',Wan Khairuzzaman Wan Ismail²
}

\begin{abstract}
The objective of this study is to assess the critical factors which influence adoption of Advanced Manufacturing Technologies (AMTs) and identify hurdles and barriers which prevent small- and medium-sized enterprises (SMEs) from accomplishing the desired goals of AMTs utilization. The proposed framework has synthesized previous studies and integrated related studies through conducting a comprehensive literature review. This paper is a theoretical construction that synthesizes previous studies, and centers on three contexts (Environmental, Organizational, and Technological) which influence adoption of AMTs. This model can provide managers with practical solutions through granting in-depth understanding of whole internal, external, and technological environments, and awarding empirical insight into overcoming barriers to the adoption and implementation of AMT and other process innovations in manufacturing organizations.
\end{abstract}

Keywords: advanced manufacturing technologies; small- and medium-sized enterprises; integrative model; manufacturing strategy.

International Business School, Universiti Teknologi Malaysia, Level 15, Yayasan Selangor Building, Jalan Raja Muda Abdul Aziz, Kuala Lumpur, Malaysia. Zip Code: 50300- Phone: +60326953321.

E-mail: 'mehdi_darbanhosseini@yahoo.com, ${ }^{2}$ makhair@ibs.utm.my.

ISSN: 07 I8-2724. (http://www.jotmi.org)

Journal of Technology Management \& Innovation (C) Universidad Alberto Hurtado, Facultad de Economía y Negocios. 


\section{Introduction}

Complexity, dynamism, and uncertainty have become dominant characteristics of recent competition patterns which resulted in a demand-diversified market with more multifaceted products (Singh et al., 2010). In the global business environment, technology is one of the salient elements for remaining competitive (Jabar et al., 20I0). Manufacturing inevitably has been influenced by re-definition of competitiveness and evolved to keep abreast of the latest market demands and arisen technologies. SMEs should re-assess their manufacturing processes and strategies and indispensably they should define an environment which is the result of integration of latest manufacturing strategies and business processes. Advanced Manufacturing Technology (AMT) has been considered as a viable solution to improve efficiency and lower costs of manufacturing firms and it has taken a determining role in this process.

Even with clarifying and identifying benefits and contribution of technologies for SMEs, there are issues regarding the effective exploitation of these technologies. Problems regarding planning, installation, and implementation stages of AMTs can prevent the SMEs from enjoying the benefits of technologies (Ungan, 2007). The outcome of companies in terms of performance using AMT does not only depend on whether the employed technology is state-of-the-art or not. In fact maximizing the performance of employed AMTs does not depend on technology itself, how well it is implemented, is a crucial factor (Waldeck and Leffakis, 2007).

Many researchers have studied various determinants of SMEs'technology adoption strategies. Nevertheless, there is a small number of published studies which introduces one comprehensive framework through integrating these findings. This research targets to develop a comprehensive framework in order to fill this gap. Therefore, this article should be of importance for both practitioner and decisionmakers, and also for future empirical studies in this field.

\section{Theoretical Background AMT}

The literature on Advanced Manufacturing Technologies (AMT) is split into separate areas, although they all are interconnected. When one considers AMT he needs to address fields such as: Investment, Assessment, Implementation, Development and Benefits of AMT. Numerous definitions for AMT have been presented. In a broad sense, AMT suggests both soft and hard technologies which are being employed to enhance manufacturing competencies (Chung et al., 2009). Previous studies reviews prove the influence of implementing AMTs on improving manufacturing productivity (Spanos, 2008; Koc et al., 2009). The term of AMT encom- passes a wide group of computer-controlled technologies, which have been introduced within the past two decades. It happened because of new achievements in information technology. AMT basically refers to technologies related to manufacturing process. Such technologies are employed to store and control data to reduce process variability and product changeover costs, which consequently would lead to enhancement in both product quality and productivity. However, some AMTs have turned out to become a total failure, whereas some achieved satisfactory results, but yet to reach desired level (Singh et al., 20I0).

The related literature depicts various classifications for AMT, based on the specific characteristic, e.g., level of integration or functionality. Some of the recent and prominent classifications will be discussed in this section. Table I shows a brief summary of different classifications of AMT.

\section{AMT Adoption: Determining Factors}

A comprehensive literature review has been undertaken to prepare an integrated framework based on previous findings. The resultant framework categorized the determining factors in AMT adoption under three main dimensions: Organizational, Environmental, and Technological context (Figure I).This outline may deliver a theoretical basis for further empirical and quantitative study.

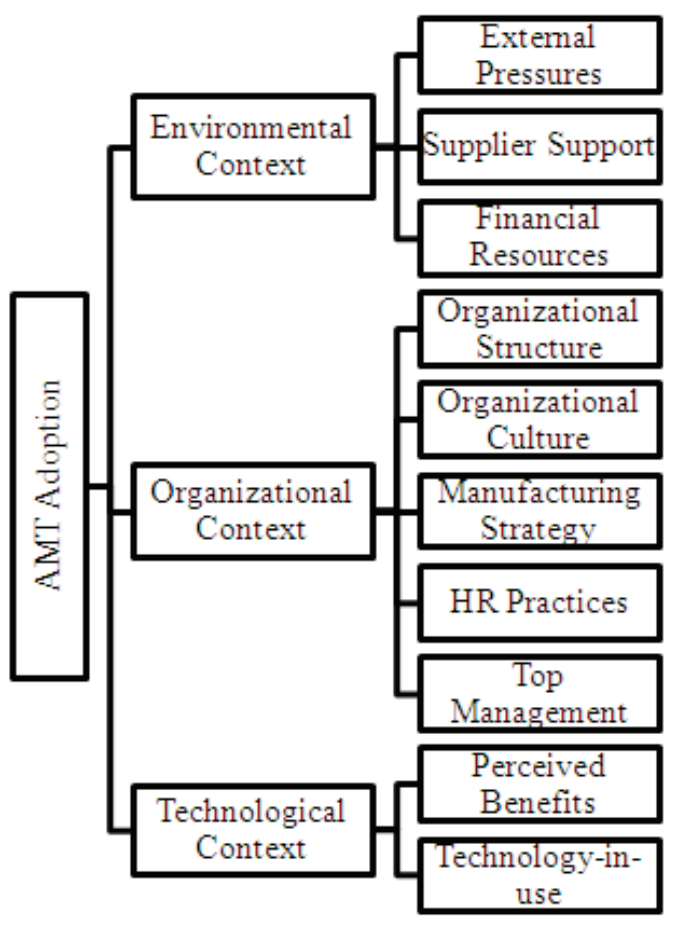

Figure I.

The proposed research framework 


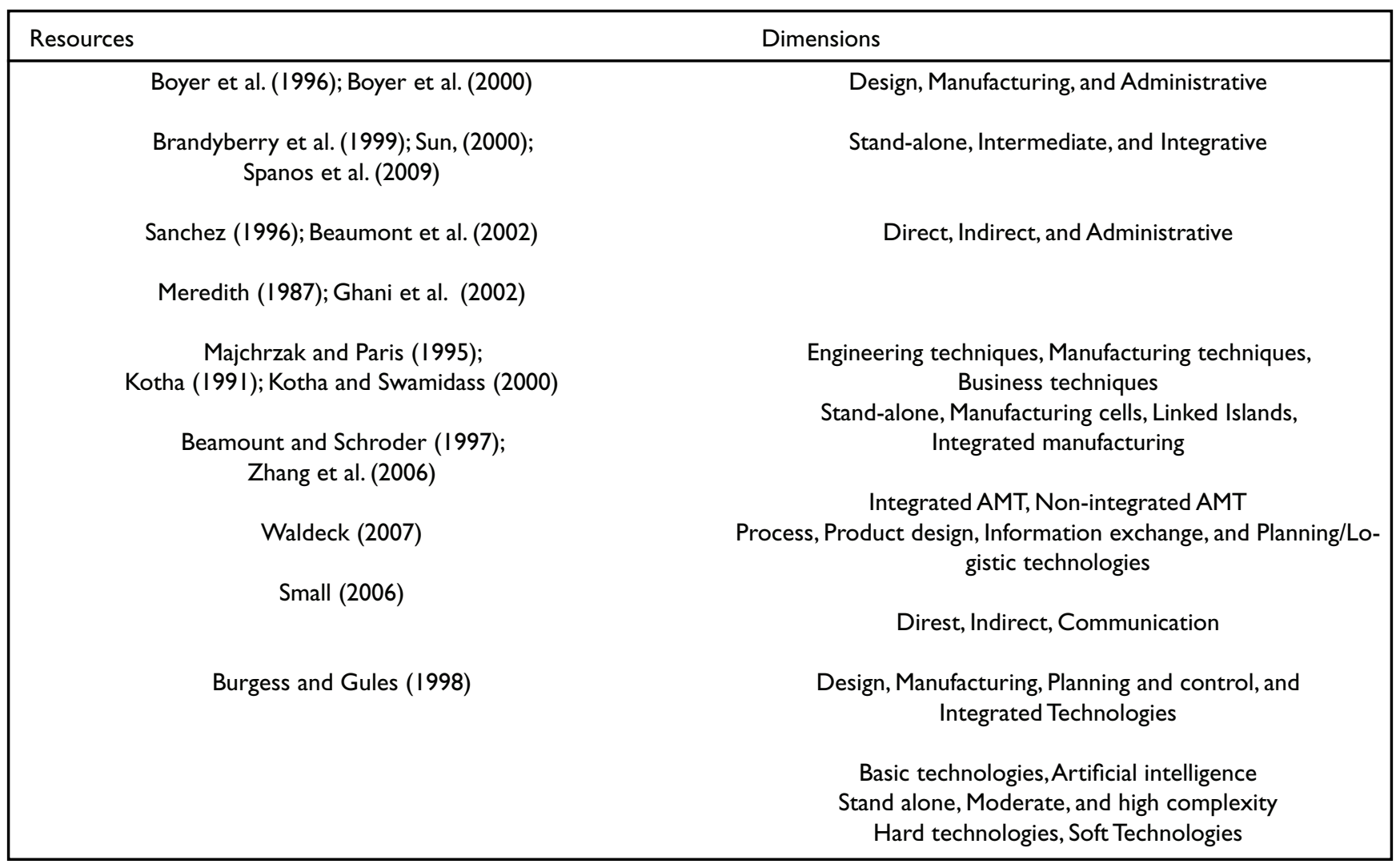

Table I.AMT Classification

\section{Environmental context}

Beyond organizational limits, factors arising from the external conditions play a substantial role in SMEs' inclination to adopt advanced technologies. A recent study reveals that adopting a higher degree of tendency toward technology cannot only be explained by the internal environment factors and external context contributes to the success of technology adoption in SMEs Moulay (Idrissia et al., 20I2). In the following section we will define the environmental context recognizing three factors: External Pressure, Supplier Support, and Financial Resources.

The related literature indicates two major external pressure sources: customer's pressure and competitive pressure (Chong et al., 2009). Other authors contend that the main external pressure source is market and it is an influencing factor regarding the adoption behavior of the firms (Spanos and Voudouris, 2009). The positive impacts of market concentration on innovation have been depicted by the Schumpeterian pattern of innovation (Parhi, 2007).

Market pressure can be divided into technological dynamism, and market hostility. In a technologically dynamic environment SMEs have to constantly improve their technology to maintain their competitiveness. They ought to enhance their product features, production process technologies, and R\&D activities. In this case SMEs' continuous upgrade of technology level and progressive adoption of complex AMTs are the probable outcome of such a highly competitive environment. To put it differently, in a hostile environment the same logic prevails; therefore, SMEs should continuously upgrade their manufacturing and production equipment to remain competitive, since the competition is extreme, shifting among rival products is easy, and a constant pressure is on profit margins.

Rahman and Bennett (2009), state that SMEs rapport with the suppliers of technology is the sole external element which has determining impact on the fate of the technology adoption. In fact, the need to establish supportive relationships with technology vendor has been found to have a crucial effect on the success of an AMT implementation project. The obvious fragile financial resource of a company, which leads to reluctance to invest in AMTs, has been stated as the main obstacle (Love et al., 200 I). Likewise, Pearson and Grandon (2004) found that availability of monetary assets is indispensably significant to managers and owners, and such subjects often determine the fate of AMT implementation, particularly in smaller manufacturing companies. 
On the other hand, others (e.g. Simpson and Doherty, 2004) showed that it is unlikely that the paucity of monetary funds hinders AMT acceptance in SMEs.A recent study shows that governments need to provide SMEs with more efficient funding instruments in order to encourage technology adoption. (Edwards-Schachter et al., 20I I).

\section{Organizational Context}

There are numerous studies in AMT literature that exactly deal with strategic issues. In the middle of those, the organizational adjustment always has had a determining role. The definitions of an organizational design have been presented to integrate the technical and social systems. Various researchers stated that the exact benefits of the AMT adoption in the manufacturing companies can be achieved and materialized only in case of compatibility of the current organizational design, with the alterations to be confronted (Small, 2006).

Human resources preparation and adjustment, organizational culture aspects, and change management role are also discussed within the subject of organizations by several authors (Waldeck and Leffakis, 2007;Waldeck, 2007; Khazanchi et al., 2007).The following paragraphs will discuss the organizational considerations of AMT adoption within five distinct areas: Organizational Structure, Organizational Culture, Manufacturing Strategy, Human Resource Practices, and Top Management Commitment.

Millen and Sohal (1998) have contended that adopting AMTs manufacturing companies have to redesign their organizational structures and organizational processes. In general, the structure of an organization can be defined as the official system of functional interactions. The groups of employees deliver to a common ultimate purpose successfully if they channelize, share and complement the tasks based on this accepted formal system. The structure of the company plays a crucial role in the implementation process of AMT adoption according to related literatures (Song et al., 2007). Shifting for correct organizational structure would help a company grasp the advantages of successful implementation of advanced manufacturing technologies (Sun et al., 2007). Traditional structure may be ever more unfitting to the new AMTs and the emerging internal environment, because this structure has been based on hierarchical management and specialization of task. Boyer et al. (1996) indicated that the several layers of decision making authorities, followed by organizations hierarchical structure, frequently creates impediments to AMT application, whereas reshuffling the company with minimum layers of authority enables the SMEs to integrate AMTs effectively.

According to Ghani et al. (2000), higher performance hap- pens when a company opts for an AMT that fits its structure and its employees. As the organizational structure of SMEs is evolutionary, rather than being revolutionary, in many industrial firms, the match between structure and technology takes several years after implementation (Hajipur et al., $20 \mathrm{II}$ ). Moreover, the acceptance of new technology in the organizations, which are naturally reactive to technological adoption and have no organized effort to exercise organizational change, would take longer time compared with more proactive and organizationally flexible firms. Preparing employees for the adoption, prior the start of the process, seems essential to reach desired goals. Effective implementation of AMT mostly involves organizational and managerial atmosphere and practices, which are dissimilar to what is being appreciated and exercised in more traditional environments. The reason behind this is that the new technologies directly defy conventional strategic options and norms. Organizational culture denotes a general concept that defines the multifaceted areas of knowledge framework which employees apply to accomplish their duties and engender social/collective behavior. Ravasi and Schultz (2006) indicate that organizational culture provides guidance for organization members act and interpret in different situations through establishing a set of shared mental assumptions.

The relationship between organizational culture and the consequences related to the implementation of advanced manufacturing technology has been surveyed by McDermott and Stock (1999). They recognized that companies can grasp various benefits employing AMTs, which are categorized as managerial or organizational benefits, competitive benefits, operational benefits, and satisfaction. They found that effects of ATM implementation, such as competitive performance or overall satisfaction, which take longer to happen, are being influenced by cultural flexibility. The authors have attempted to clarify the connection between the success rate of AMT introduction and organizational culture. What most analysis illustrates is that the cultures that are more controloriented likely will succeed only partially in AMT implementation. Recent studies reveals that successful manufacturing companies which were successful in AMT implementation had opted for a more flexibility-oriented organizational culture that might have comforted the AMT implementation through creating an atmosphere of encouragement and trust (Yusuff et al., 2008; Peixin Li and Wei Xie, 20I2).

In the manufacturing function scope, a manufacturing strategy can be outlined as policies that complement and support the firm's competitive position (Costa and Lima, 2008). The significance of manufacturing strategies for the organizations' general success have attracted extensive attention from authors since the publication of Skinner's breakthrough studies in 1969, which is regarded as the missing link of manufacturing in corporate strategy. However, new approaches

ISSN: 07 I8-2724. (http://www.jotmi.org)

Journal of Technology Management \& Innovation (C) Universidad Alberto Hurtado, Facultad de Economía y Negocios. 
of manufacturing strategy imply that investments in SMEs should be more in the capacity of the firms to create higher competencies in order to grasp enduring competitive advantages. The manufacturing strategy literature has suggested a direct link between firm performance and manufacturing strategy. Several authors have recognized the importance of this idea and they tried to analyze the connection between manufacturing strategy and firm performance (Amoako-Gyampah and Acquuah, 2008; Olhager and Prajogo, 20I2). Borrowing from Fleury and Fleury (200I), a company consists of a set of tangible and intangible resources that can be organized in order to create and sustain a competitive advantage. Slack et al. (200I) indicate that the resources and capabilities of a firm are the basis of sustainable competitive advantage. Generally, it is accepted that operations/manufacturing strategies of a company consist of four significant competitive priorities: Quality, Cost, Dependability/Delivery and Flexibility (Dangayach et al., 2003). Ability to deliver exceptional services or products, likely at premium price, refers to the Quality strategy of a company. As its title implies, the Cost strategy focuses on lowering the costs in the production and distribution of products. It is a measure of the efficiency of manufacturing operations, and conventionally it has been related to mass production and high volume. The Dependability/Delivery strategy deals with delivery schedule, which has to be accurate and on-time. This strategy also refers to the responses, which should be swift, of a firm to its customer orders. And finally, the Flexibility is the degree of a company's capability in moving, through matched actions and policies, from one product to another. Moreover, it measures the firm's swiftness of reaction to modifications of product mix and productions, to alterations in design, and to fluctuations in materials and changes in order to address the market demands. Firms may vary in terms of the amount of stress employed on these priorities. This amount hinges on a large number of issues comprising: business strategy, managerial behavior, accessibility of resources, existing capability, environmental condition, and intensity and nature of competition.

The Flexibility strategy, compared with the aforementioned manufacturing strategies, has been considered as the most important variable of every SME coping with environmental uncertainties, which are specifically relevant to the swiftly changing environments affecting manufacturing companies. Flexibility is the biggest advantage that an AMT delivers to a properly implemented company. However, the opportunities following the adoption of AMT can only be converted to advantages if the SME employs strategic planning tactics. A manufacturing organization will be swift in addressing the demands of the market if it welcomes an approach that permits the organization to grasp mix and volume flexibility, while maintaining the high quality and low cost of products, and the result will be a manufacturing company with higher performance (Amoako-Gyampah and Acquuah, 2008). Khazanchi et al. (2007) analyzed successful AMT adopters (high performers) and compared them with failed cases (low performers) and concluded that among the two clusters in their sample of SMEs in employing AMTs, high performers were in general more likely to prefer the flexibility, delivery and quality strategies rather than cost strategy. They also demonstrated that the two groups of AMT adopters had noticeably distinct approaches regarding quality strategy. However, other scholars are of the idea that reaping the benefits of AMT adoption of SMEs can be affected by all four manufacturing strategy dimensions and all have an impact on implementing new technologies and on achieving related benefits, thus AMT performance cannot be directly related to one dimension alone.

Successful adoption of AMTs requires employee support. In fact, lack of employee backing prior to the implementation of technologies would have detrimental effects (Ghani, 2000; Barua and Islam, 2008). Researchers state that the behaviors, attitudes, and qualities of human resources can add edge to the competitiveness of the company and make its advantages more distinctive compared with its rivals (Cascio, 2010; Noe et al., 2008). Inadequate concentration on the human facet of ATM implementation has been recognized as a major failure reason in terms of reliability, flexibility, quality and responsiveness (Waldeck and Leffakis, 2007). The involvement of managers in R\&D operations and development of employees in socialization activities are examples of workforce development techniques. This approach can improve relational requirements and skills of human capital of the company, which is supposed to exploit the new technologies (Chen et al., 2008).

AMT implementation, basically, requires highly skillful workers whom should be provided with more autonomy facing issues such as AMT plans and problem solving (Waldeck and Leffakis, 2007). Moreover, they should become more adept with respect to skills, responsibility, knowledge, and attitudes. Consequently, catering to employees' job satisfaction and intrinsic motivations by creating opportunities of employee involvement can be considered as a viable method to affiliate the goals of human elements with the company which is adopting AMTs (Waldeck, 2007). The related studies illustrate that education and training programs consume 25 to 40 percent of the full cost of a widespread effective AMT implementation venture (Boothby et al., 20l0).

We may distinguish two main rudimentary requirements for every newly AMT adopted SME: hard needs and soft needs (Rezaei et al., 2012). Different hardware equipment and facilities that are related to preparation of the adopted AMT refers to the rudimentary hard needs of SMEs, whereas required skills and knowledge of employees of SMEs, which 
are necessary to succeed in exploiting the AMT, refer to rudimentary soft needs. One of the key responsibilities of human resource managers is the development of such knowledge for SMEs and its workforce. Training programs are the popular medium to deliver the necessary skills and knowledge which result in skillful workers who are acquainted with the fundamentals of manufacturing process, computerrelated technologies, and automation. These programs effectively can enhance not only personal but also organizational capabilities of SMEs in different facets. Moreover, on time delivery and inside the company conflict reduction, besides to this elevation in workers' skills can be achieved (Marri, 2007).

Top management support, enthusiasm, motivation, and encouragement toward adoption of AMT play a key role (AlQirim, 2007; Ramdani et al., 2009).Top management commitment in supporting AMT implementation is one of the best predictors of the adoption success (Jeyaraj et al., 2006). Understanding the importance of AMT by the top management would inspire it to play an important role in persuading employees to welcome new technology, moreover managers would allocate willingly enough resources to the adoption. To reap the potential benefits of an adopted AMT, top managers should focus on long term strategic plans emphasizing flexibility, responsiveness, and quality. However, top manager should prepare company even before the implementation of AMT by enhancing enterprise's performance and technological strategy. The paucity of internal technological knowledge and long-standing vision of receiving novel technology are considered as the main cause of AMT failure in manufacturing companies (Marri, 2007).

\section{Technological Context}

The advantages that AMT can deliver are referred as Perceived Benefits. The adoption of a technology can be positively influenced if adopters recognize the benefits of such technology over current systems and practices. Scholars (e.g., Al-Qirim, 2007; Chong and Pervan, 2007) have indicated that one of the powerful predictors of the AMT's adoption success is the perceived benefits category.

Meredith and Hill (1987) argued through the incremental model that investments in AMT at all three levels of standalone, intermediate, and integrated technologies follows a sequential progression. According to this model, any particular technology should first be confirmed successful prior to adoption and integration of the next generation AMT, which would probably be more complicated one.

On the other hand, there is another argument that is the discontinuous model of AMT adoption. It is based on the fact that integrated AMT has to be planned accurately and needs to be provided with committed resources. Thus, adopting integrated systems can be considered as a big transformational change, in which all systems are put into action instead of progressing incrementally (Spanos and Voudouris, 2009). Therefore, the adoption of more basic AMTs, such as stand-alone technologies or even intermediate ones, can be planned and exercised easily at a lower levels of management, whereas the adoption of integrated systems require risky and complex investment decisions, independent of inuse technologies and demands involvement of top level of decision makers. Reviewing the literature related to technology adoption in developing countries reveals that technology competency development in such economies follows an evolution ranging from imitation till innovation (Bell, 2006).

\section{Conclusions and implications}

This study comprehensively reviews 10 factors, categorized in three contexts, which influence the adoption of AMTs by SMEs. The developed framework creates a conceptual basis for further practical researches.

This framework can be employed by business managers to address questions before making decisions on AMT adoption, such as: why should we adopt AMT? Is it reasonable strategic decision for our organization? What are the expected obstacles and benefits?

I- Are the internal characteristics welcoming AMT adoption? Does the company have an innovation-supportive culture? How do the manufacturing strategies and HR practices assist the technology adoption process of the company? Is the top management committed to overcome the risks involved in AMT adoption? Preparing the employees for a novel practice instead of old ones is a key element to diminish reluctance to implement AMT. The performance of human resource department is critical to enhance self-efficacy of workforce which will result in satisfactory de-training and re-training processes.

2- Is the market friendly toward the application of new technologies? Is the market growing? Are there reliable and accessible vendors in the market? Does the company have access to financial resources?

3- What are the predicted benefits of the new technology? How the currently using technology can assist to adopt the new ones?

Analyzing our answers to these questions reveals that all the aforementioned factors are interrelated. However, it does not necessarily mean that all answers must be favorable in order to implement AMT. Managers should synthesize the answers to grasp in-depth understanding of whole internal, external, and technological situations. 


\section{For future research}

Industry factor seems to have been neglected by researchers. There are not many published studies from the industry point of view on AMT adoption. The sector or industry type in which a company performs may impact its success in AMT implementation.

Moreover, the size of a firm in terms of workforce number and sales revenue may influence the company's adoption strategy. Smaller companies tend to employ technology to gain competitiveness, whereas larger businesses regard AMT as a source to lower manufacturing costs (Li and Xie, 20I2). Although some authors argue that the firm age has a significant role in the assimilation of technology (Simpson and Doherty, 2004), more recent research by Li et al. (20I0) reveals that there is not significant association between these two variables.

\section{References}

AMOAKO-GYAMPAH, K., Acquaah, M. (2008). Manufacturing strategy, competitive strategy and firm performance:An empirical study in a developing economy environment. International Journal of Production Economics, I I I (8), 575-592.

AL-QIRIM, N. (2007). The adoption of eCommerce communications and application technologies in small businesses in New Zealand. Electronic Commerce Research and Applications, 6(4), 462-73.

BARUA, B., Obaidul Islam, M. M. (2009). Key Success Factors for Implementation of Advanced Manufacturing Technologies (AMTs) Case Study Conducted on Selected Pharmaceutical Companies in Bangladesh. AIUB Journal of Business and Economics, 8(2), 53-67.

BELL, M. (2006). How long does it take? How fast is it moving (if at all)? Time and technological learning in industrializing countries. International Journal of Technology Management, 36 (I-3), 25-39.

BEAUMONT, N., Schroder, R. (1997). Technology, manufacturing performance and business performance amongst Australian manufacturers. Technovation, I7(6), 297-307.

BEAUMONT, N., Schroder, R., Sohal, A. (2002). Do foreignowned firms manage advanced manufacturing technology better. International Journal of Operations \& Production Management, 22(7), 759-77I.

BOOTHBY, D., Dufour, A., Tang, J. (2010). Technology adoption, training and productivity performance. Research Policy, 39(I0), 650-66I.
BOYER, K., Ward, P., Leong, G. K. ( 1996). Approaches to the factory of the future An empirical taxonomy. Journal of Operations Management, I4(1996), 297-3I3.

BOYER, K., Pagell, M. (2000). Measurement issues in empirical research: Improving measures of operations strategy and advanced manufacturing technology. Journal of Operations Management, I8(3), 36I-374.

BRANDYBERRY, A., Rai, A., White, G.P. (1999). Intermediate performance impacts of advanced manufacturing technology systems: an empirical investigation. Decision Sciences, 30(4), 993-1020.

BURGESS, T. F., Gules, H. K. (1998). Buyer-supplier relationships in firms adopting advanced manufacturing technology: An empirical analysis of the implementation of hard and soft technologies. Journal of Engineering and Technology Management, I5(4), I27-I52.

CASCIO,W. F. (20I0). Managing human resources: Productivity, quality of work life, profits. McGraw-Hill/Irwin, New York.

CHEN, C. P., Liu, P. L., Tsai, C. H. (2008). A study of the influence of organizational knowledge ability and knowledge absorptive capacity on organizational performance in Taiwan's hi-tech enterprises. Journal of Applied Sciences, 8(I) II 38-48.

CHONG, S., Pervan, G. (2007). Factors influencing the extent of deployment of electronic commerce for small and medium-sized enterprises. Journal of Electronic Commerce in Organizations, 5(I), I-29.

CHONG, A., Ooi, K. B., Lin, B., Tang, S.Y. (2009). Influence of interorganizational relationships on SMEs' e-business adoption. Internet Research, 19(3), 3|3-3I.

CHUNG,W., Swink, M. (2009). Patterns of Advanced Manufacturing Technology Utilization and Manufacturing Capabilities. Production and Operations Management, 18(5), 533545.

COSTA S.E.G., Lima, E.P. (2009). Advanced manufacturing technology adoption: an integrated approach. Journal of Manufacturing Technology Management, 20 (I), 74-96.

DANGAYACH, G. S., Deshmukh, S.G. (2003). Evidence of manufacturing strategies in Indian industry. International Journal of Production Economics, 83(3), 279-298.

EDWARDS-SCHACHTER, M., Castro- Martínez, E., Fernández-de-Lucio, I. (20I I). International Co-operation between Firms on Innovation and R\&D: Empirical Evidence from Ar-

ISSN: 07 I8-2724. (http://www.jotmi.org) 
gentina and Spain. Journal of Technology Management \& Innovation, 6 (3), I26-147.

FLEURY, A.C.C., Fleury, M.T.L. (200I). Business Strategies and Competences Development: The Kaleidoscope Puzzle of the Brazilian Industry.Atlas, Sã Paulo.

GHANI, K. A., Jayabalan, V. (2000). Advanced manufacturing technology and planned organizational change. The Journal of High Technology Management Research, II (I), I-I8.

GHANI, K.A., Jayabalan, V., Sugumar, M. (2002). Impact of advanced manufacturing technology on organizational structure. The Journal of High Technology Management Research, I3(2), I57-I75.

HAJIPOUR, B., Talari, M., Shahin,A. (20I I).An investigation of the relationships between industry structure, strategy type, organizational characteristics and organizational performance: $A$ case study of the food and chemical industries of Iran.African Journal of Business Management, 5(16), 7085-98.

IDRISSIA, M. O.,Amaraa, N., Landrya, R. (20I2). SMEs' Degree of Openness:The Case of Manufacturing Industries. Journal of Technology Management \& Innovation, 7(I), I86-210.

JABAR, J., Soosay, C., Santa, R. (20 I0). Organizational learning as an antecedent of technology transfer and new product development: A study of manufacturing firms in Malaysia. Journal of Manufacturing Technology Management, 22(I), 2545.

JEYARAJ, A., Rottman, J.W., Lacity, M.C. (2006). A review of the predictors, linkages, and biases in IT innovation adoption research. Journal of Information Technology, 2 I (I), I-23.

KHAZANCHI, S., Lewis, M. W., Boyer, K. K. (2007). Innovation-supportive culture: the impact of organizational values on process innovation. Journal of Operations Management, 25 (4), 87I-84.

KOC, T., Bozdag, E. (2009). The impact of AMT practices on firm performance in manufacturing SMEs. Robotics and Computer-Integrated Manufacturing, 25(9), 303-3।3.

KOTHA, S. (199I). Strategy, manufacturing structure and advanced manufacturing technologies. Academy of Management Best Paper Proceedings, 17 (2), 293-297.

KOTHA, S., Swamidass, P. M. (2000). Strategy, advanced manufacturing technology and performance: empirical evidence from U.S. manufacturing firms. Journal of Operations Management, 18(3), 257-277.
LI, P., Xie,W. (20/2). A strategic framework for determining e-commerce adoption. Journal of Technology Management in China, 7 (I), 22-35.

LI, D., Lai, F., Wang, J.E. (20I0). E-business assimilation in China's international trade firms: the technology-organizationenvironment framework. Journal of Global Information Management, 18 (I) 39-65.

LOVE, D., Irani, Z., LI, H., Cheng, L., Tse, Y. (200I). An empiri$\mathrm{cal}$ analysis of the barriers to implementing e-commerce in small-medium-sized construction contractors in the state of Victoria, Australia. Construction Innovation, I(I), 3I-4I.

MAJCHRZAK, A., Paris, M. L. (1995). High-performing organizations match technology and management strategies: Results of a survey. International Journal of Industrial Ergonomics, 16(4-6), 309-325.

MARRI, H. B., Gunasekaran,A., Sohag, R.A. (2007). Implementation of Advanced Manufacturing Technology in Pakistani Small and Medium Enterprises:An Empirical Analysis, Journal of Enterprise Information Management, 20(6), 726-739.

MCDERMOTT, C. M., Stock, G. N. (1999). Organizational culture and advanced manufacturing technology implementation. Journal of Operations Management, I7(5), 52I-533.

MEREDITH, J. R. (1987). The strategic advantages of the factory of the future. California Management Review, 29, 27-4I.

MILLEN, R., Sohal, A. (1998). Planning process for advanced manufacturing technology by large American manufacturers. Technovation, I8(I2), 74I-50.

NOE,A. R., Hollenbeck, J. R., Gerhart, B.,Wright, P. M. (2008). Human Resource Management: Getting a Competitive Advantage. McGraw-Hill, New York.

OLHAGER, J., Prajogo, D. (20I2). The impact of manufacturing and supply chain improvement initiatives: A survey comparing make-to-order and make-to-stock firms. Omega, 40(2), I59-165.

PARHI, M. (2007). Global push, Competitiveness, and Adoption of New Technologies: Reflections from Indian Automotive Firms. DRUID Summer Conference, June $18-20$. Copenhagen, CBS, Denmark, I-2I.

PEARSON, M., Grandon, E. (2004). E-commerce adoption: perceptions of managers/owners of small and medium-sized firms in Chile. Communications of the Association for Information Systems, I3(8). 81-102. 
RAHMAN, A. A., Bennett, D. (2009). Advanced manufacturing technology adoption in developing countries: The role of buyer-supplier relationships. Journal of Manufacturing Technology Management, 20(8), I099-I I I8.

RAMDANI, B., Kawalek, P., Lorenzo, O. (2009). Predicting SMEs' adoption of enterprise systems. Journal of Enterprise Information Management, 22(I/2), 10-24.

RAVASI, D., Schultz, M. (2006). Responding to organizational identity threats: Exploring the role of organizational culture. Academy of Management Journa, 49 (3), 433-458.

REZAEI, M., Shamsaei, F., Mohammadian, I., Van Vyve, M. (20/2). A heuristic method to schedule training programs for Small and Medium Enterprises. European Journal of Operational Research, 217(20I2), 600-608.

SANCHEZ, A.M. (1996). Adopting AMTs: experience from Spain. Journal of Manufacturing Systems, I5(2), I33-40.

SINGH, H., Khamba, J. S. (20I0). Research Methodology for Effective Utilization of Advanced Manufacturing Technologies in Northern India Manufacturing Industry. The IUP Journal of Operations Management, 9(2), 43-56.

SIMPSON, M., Doherty, A. J. (2004). E-commerce adoption support and advice for UK SMEs. Journal of Small Business and Enterprise Development, II(3), 3I5-28.

SKINNER, B.F. (1969) Contingencies of Reinforcement. Englewood Cliffs, N.J.: Prentice-Hall.

SLACK, N., Chambers, S., Johnston, R. (200I). Operations Management. Prentice-Hall, Harlow.

SMALL, M.H. (2006). Justifying investment in advanced manufacturing methodology: a portfolio analysis. Industrial Management \& Data Systems, 106(4), 485-508.

SONG, J. B., Dai, D. S., Song, Y. Q. (2007). The relationship between change of organizational structure and implementation of advanced manufacturing technology: An empirical study. International Conference on Management Science and Engineering. 2007, Lille, 103-I 19.

SPANOS, Y. E., Voudouris, I. (2009). Antecedents and trajectories of AMT adoption: The case of Greek manufacturing SMEs. Research Policy, 38 (9) I44-I55.

SUN, H. (2000). Current and Future Patterns of Using Advanced Manufacturing Technologies. Technovation, 20(II), $63|-64|$.
SUN, X. L., Tian, Y. Z., Cui, G. G. (2007). The empirical study on the impact of advanced manufacturing technology on organizational structure and human resources management. International Conference on Management Science and Engineering, 2007. Lille, 57- 69.

UNGAN, M.C. (2007). Manufacturing best practices: implementation success factors and Performance. Journal of Manufacturing Technology Management, 18(3), 333-48.

WALDECK, N. E. (2007). Worker assessment and the provision of developmental activities with advanced technology: an empirical study. International Journal of Production Economics, 107(2), 540-54.

WALDECK, N. E., Leffakis, Z. M. (2007). HR perceptions and the provision of workforce training in an AMT environment: an empirical study. OMEGA:An International Journal in Management Science, 35(2), I6I-72.

YUSUFF, R. M., Saberi, S., Zulkifli, N. (2008). A comparison on the capabilities of Malaysian SMEs with different equity structure in implementing advanced manufacturing technologies. Asian International Journal of Science and Technology in Production and Manufacturing Engineering, I(I5), 63-75.

ZHANG, Q., Vonderembse, M. A., Cao, M. (2006). Achieving flexible manufacturing competence: the roles of advanced manufacturing technology and operations improvement practices. International Journal of Operations \& Production Management, 26(6), 580-99. 